\title{
AN INTEGRATED MANAGEMENT APPROACH TO LEVERAGING KNOWLEDGE INNOVATION
}

\author{
Andrew L S Goh \\ International Graduate School of Management, \\ University of South Australia \\ Adelaide, Australia \\ Email: andrewgoh1@hotmail.com
}

\begin{abstract}
:
Knowledge management $(\mathrm{KM})$ is widely accepted as an indispensable management discipline. It has now emerged as the next likely source of sustainable competitive advantage. However, as to how knowledge management (KM) practices can be harnessed to leverage the pursuit of knowledge innovation has yet to be fully explored. This article discusses the significance of knowledge by describing the transition from "information revolution" to "knowledge revolution" - which enables various forms of knowledge to be absorbed, assimilated, shared and utilised. Next, it highlights the practice of knowledge management (KM) and explains why KM could enable knowledge innovations to evolve, and how information technology (IT) should be exploited for this purpose. It then proposes a management framework for leveraging knowledge innovation (KI) by focusing on knowledge-centred principles, knowledge-sharing infrastructures and knowledge-based initiatives, to offer insights into integrating concepts of knowledge management (KM) with innovation management (IM). In conclusion, it outlines the challenges of knowledge innovation (KI) that merit attention for organisations to better exploit its full benefits.
\end{abstract}

Keywords: Knowledge innovation (KI), knowledge management (KM), innovation management (IM), knowledge-centred principles, knowledge-sharing infrastructures, knowledge-based initiatives, information and communication technologies (ICT).

\section{INTRODUCTION}

\section{Emergence of Knowledge Management (KM)}

In the last decade or so, with the significant role played by knowledge-intensive businesses in the economy, the term "knowledge management (KM)" has generated a lot of keen interest in the corporate sectors. However, with no universally accepted definition for knowledge management $(\mathrm{KM}$,) the term is often conceived in the broadest context, for instance, as a process through which organisations generate value from knowledge-based assets. But in actual fact, KM embodies the critical issues of organisational processes that seek synergistic combination of data and information processing capacity through the use of appropriate technologies, and the creative and innovative capacity of human beings (Barth, 2000; Amidon, 1997). Given that the Internet has been evolving steadily for over two decades since its origins in the US APRAnet project in the 1960s and now increasingly used as a KM tool, the field of knowledge management has strongly emerged as a "hot discipline". In the prevailing knowledge-intensive business environment, many see it as the next likely source of sustainable competitive advantage.

At the same time, "innovation management (IM)"- which is a field of discipline that deals primarily with issues relating to how the innovation process could be managed effectively, has attracted much attention too. Like knowledge management (KM), innovation management (IM) has been consistently demonstrated to be a key value creator in organisational growth and business performance (Goh, 2004; Harkema and Browaeys, 2002; Giget, 1997). With technological innovations as the mainstay of today's business, innovation management (IM) has become an 
organisation's integral function. However, both KM and IM represent areas of management that seemed to reside in separate spheres of influence, with almost no impact or influence on one another. Yet, one major area of management concern confronting today's organisations lies in the efficient use of knowledge-based assets to create better, faster and more cost-effective innovations.

\section{Integration of KM and IM}

The immediate concern, as global competition intensifies, appears to be more than just dealing with $\mathrm{KM}$ or IM issues separately. Rather, it involves acquiring the ability to harness KM practices for IM processes as a deliberate management strategy that would bring about a higher level of organisational performance. In the past, organisations that rely on the success of innovations to sustain organisational performance often ask themselves the question: "How can innovation improve our organisational performance?" With this new strategic management focus, organisations are now asking the question: "How can the pursuit of knowledge innovations enable us to sustain our longterm competitive advantage in the new business world?" (Goh, 2004; Harkema and Browaeys, 2002; Clarke and Rollo, 2001; Davenport and Prusak, 1998)

Given the heightened interest to draw lessons from the management of knowledge innovation (KI), it seems opportune to integrate the two strands of thinking behind knowledge management (KM) and innovation management (IM). To establish threads of potential integration between knowledge and innovation management concepts, this article explores the linkages between KM and IM issues to shed light on how they can be drawn closer together. With this purpose in mind, the subsequent sections offer viewpoints to foster a more profound understanding and better appreciation of knowledge innovation. Figure 1 provides a pictorial view for potential integration of the two disciplines, namely: innovation management (IM) and knowledge management (KM) to enable organisations in adopting a more integrated approach towards the management of KI as a source of sustainable competitive advantage.

Figure 1: Knowledge Innovation (KI) as a Competitive Tool

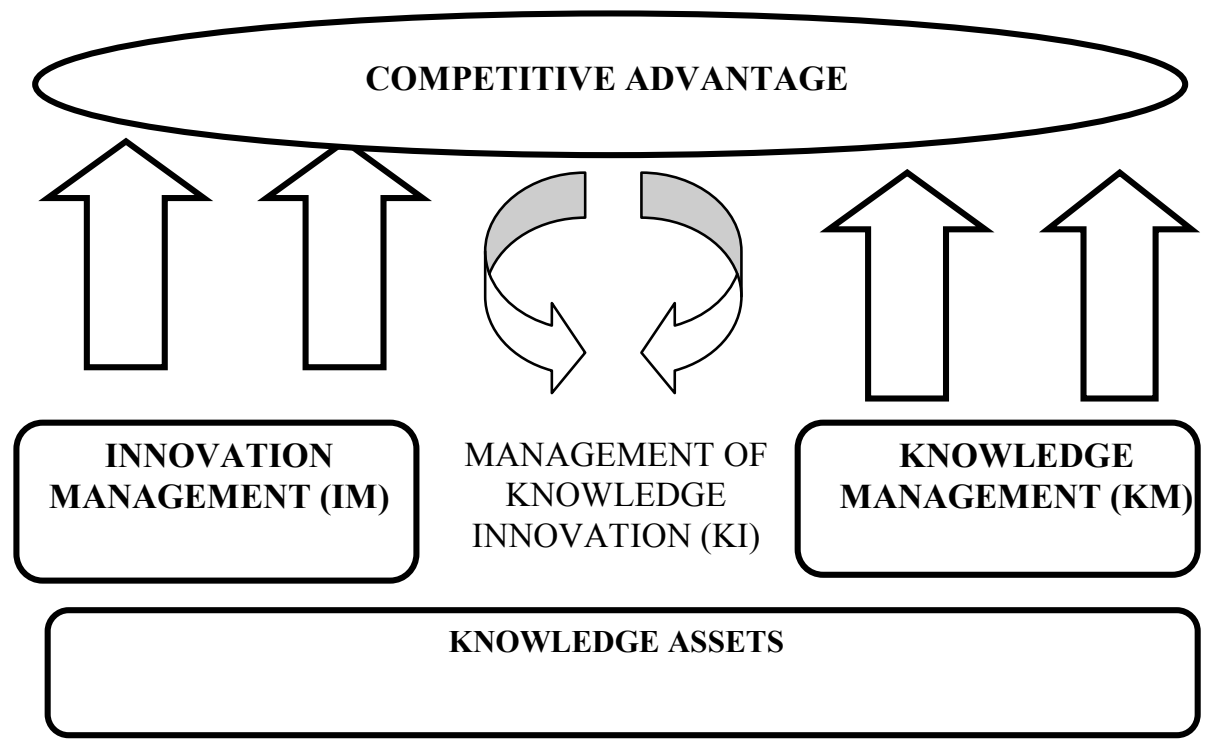




\section{THE SIGNIFICANCE OF KNOWLEDGE}

\section{Transition to Knowledge Revolution}

In the new economy, knowledge is the primary resource for economic development; and land, labour and capital - the economist's traditional factors of production - do not disappear, but they simply become secondary (Drucker, 1994). Traditional factors of production are limited by a threshold of scale and scope as every marginal increase in land, labour or capital results in diminishing returns on additional investment. By contrast, the returns from knowledge are governed by a different law of economics: investment in every additional unit of information or knowledge created and utilised results in a much higher return. This is largely due to "externalities" of an information or knowledge network since the strength and utility of the network rises with increasing membership (Yogesh, 2000). The "what" that impacts on traditional types of innovation has shifted from the "tangibles and physical assets" to "processes wherein various forms of knowledge are absorbed, assimilated, shared and utilised with the objective of creating knowledge innovation". Under such a scenario, knowledge capital naturally becomes as a source of sustainable competitive advantage for organisations.

While innovation practitioners recognise the importance of knowledge, the apparent confusion between the value of "knowledge" and "information" has caused organisations to sink billions of dollars in information technology (IT) investments that have yielded marginal economic results. For instance, IT economist Paul Strassmann concluded that there is no relationship whatsoever between computer expenditures and company performance (Strassman, 1997). This prevailing disconnect between IT expenditures and the firms' organisational performance could be attributed to an economic transition from an era of competitive advantage based primarily on information processing to one based on knowledge creation (Malhotra, 2000a; 1997). In fact, the rising interest in knowledge innovation as a strategic lever in organisational performance is not entirely new. Back as the mid-nineties, support for knowledge innovation was already prevalent. For instance, British Petroleum's CEO Sir John Browne said that: “anyone in an organisation who is not directly accountable for making profits should be involved in creating, distributing and utilising knowledge that the company may use to make profits." In other words, he advocates that all employees in an organisation must participate, directly or otherwise, in knowledge processes to innovate for economic gains - such a stance fundamentally places the role of knowledge innovation as important, if not more important, as the role of marketing, sales or any profit-driven activity. It has thus become increasingly evident to organisations that the "information revolution" has been superseded with "knowledge revolution" as depicted in Figure 2. To succeed in the knowledge economy, organisations who are able to capitalise on the opportunities arising from the availability of knowledge-based assets and ultimately derive the most value from them will be the industry winners. But to harness the most value from these assets, organisations must identify the types of knowledge assets that benefit businesses and understand how KM practices can be implemented effectively to improve operational efficiency, reduce costs, achieve higher productivity and boost revenues. Hence, an important implication of $\mathrm{KM}$ research is to contribute findings that would help practitioners develop and improve the use of knowledge-based assets. 
Figure 2: Towards a Knowledge Revolution

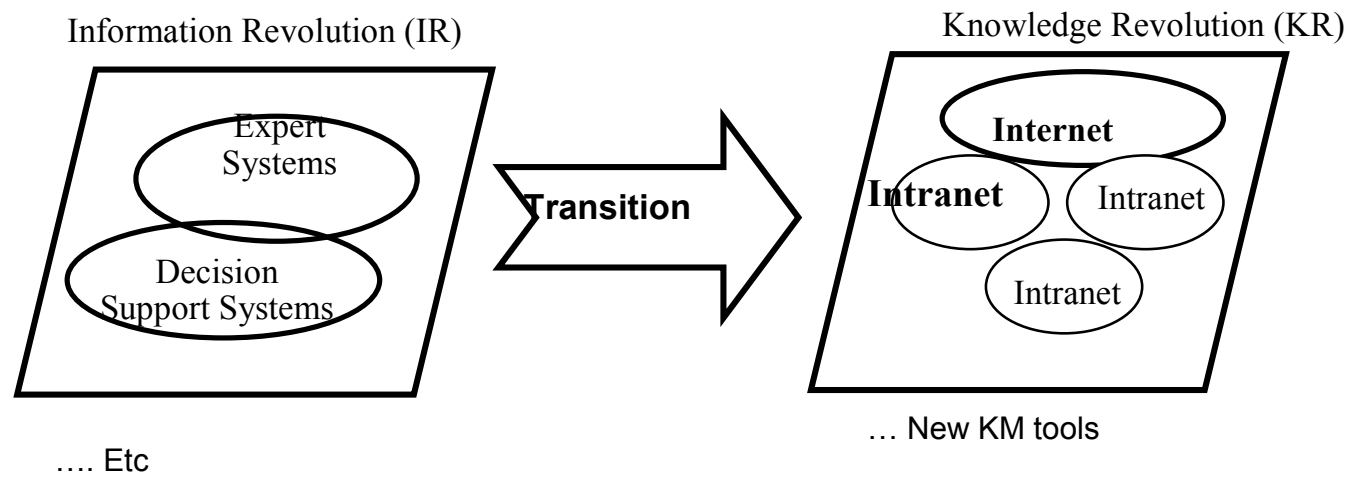

\section{The Practice of Knowledge Management}

With the changing forms of knowledge in today's society, the role of managing knowledge has become a key engine for innovation and growth. Knowledge adds value to an organisation through its contribution to products, processes and people, while knowledge management (KM) transforms information, data and intellectual assets into enduring value by identifying "useful knowledge" for management actions (O’Dell, 1996). The high economic value placed on knowledge has prompted organisations to support the design and use of knowledge management systems to enable people to create and apply knowledge effectively. In recent years, the practice of knowledge management (KM) has evolved to be of considerable interest to management writers, thinkers and practitioners. Coupled with organisations' need to innovate, this interest on knowledge management (KM) practices has been propelled alongside that of innovation management (KM). With better recognition placed on the value of knowledge management (KM) practices to business, organisations are now investing in ad-hoc project initiatives to manage, harness and exploit knowledge for business use.

So far, the contribution made by knowledge management (KM) practices, to improve organisational performance, has been significant. One example of the escalating intensity of knowledge in products is the intelligent car, whose engine management systems can monitor the functions of vital engine parts and "knows" in advance which part needs servicing and thus improves the car performance. Another example of knowledge in processes is the sharing of best practices, such as in high-tech semiconductor fabrication plants, which brought about huge savings in capital investments. In the case of people, the "skilled knowledge" of experienced persons in commercial transactions (e.g. negotiation) often contributes to whether knowledge-intensive businesses would succeed or fail.

With the benefits of knowledge management (KM) practices to business, it has resulted in a proliferation of KM tools such as expertise access tools, e-learning applications, Web portals, discussion and chat technologies, electronic message boards, synchronous interaction tools, and search and data mining tools. While the benefits of KM correlate directly to bottom-line savings, there is also a risk associated with investments in knowledge management (KM), as they do not necessarily lead to expected benefits due to failures in implementation (Lindgren and Henfridsson, 2002; Storey and Barnett, 2000; Fahey and Prusak, 1998). Nevertheless, the economic impact of 
$\mathrm{KM}$ practices to business is manifested in three areas of any organisation. They are, namely: products like patents or technology licences (intellectual capital), processes like financial procedures or manufacturing methods (structural capital) and people like skilled manpower or specialised talents (human capital) as illustrated in Figure 3.

Figure 3: Benefits of KM Practices

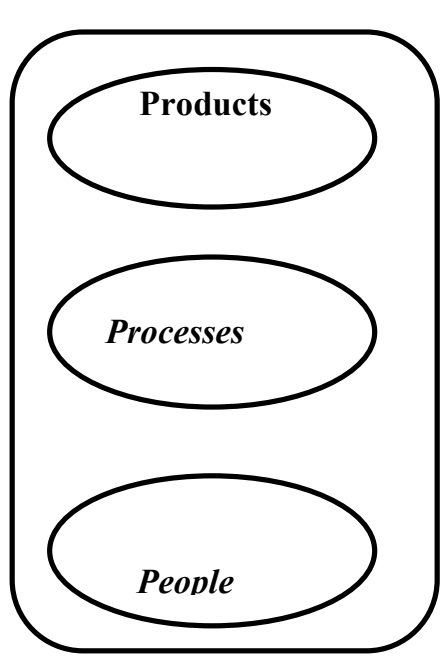

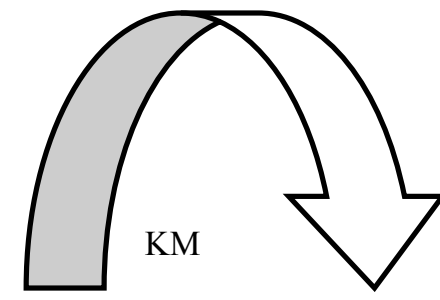

Practices

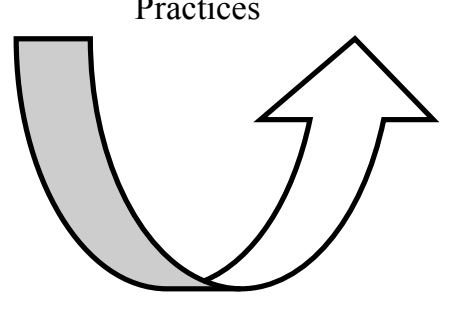

Intellectual

Capital

Structural

Capital

Human Capital 


\section{Evolution of Knowledge Innovation}

Today's organisations are in an unending struggle to differentiate themselves from relentless competitors as markets become saturated with innovations all the time. The ability to differentiate depends on the availability of knowledge-based assets and how organisations employ KM practices to harness the value of these assets. Thus organisations have been trying to differentiate themselves based on unique production processes, rare and distinct skills, creativity, and now on management initiatives such as supply chain management and customer relationship management (Gold, Malhotra \& Segars, 2001).

As global competition intensifies in most corporate sectors, knowledge management (KM) would have to play a more pivotal role in the pursuit of innovation. With mounting pressure to acquire KM capability for innovation management (IM), many organisations are also fast working towards being recognised as an exemplar of knowledge management (KM) practices. For instance, organisations are implementing ad-hoc knowledge-based initiatives like setting up a corporate Intranet or initiating communities of KM practices or redesigning a core business function around knowledge sharing. However, a majority of these KM programmes are still predominantly centred on building computerised databases or electronic repositories for documenting, storing and disseminating best practices.

For organisations to earn a sizeable payback for their KM efforts, the real payoff lies in applying knowledge to innovation. This requires a management focus on the processes associated with knowledge creation, transmission and sharing in fostering organisational innovation. To cite an example, Nokia, an organisation that has consistently applied KM practices in its business, has yielded considerable benefits in innovation-related and product development functions. Nokia makes use of KM practices extensively to understand market trends and customer requirements and puts useful knowledge into action for its innovation pipeline. It is thus not surprising that industry analysts reported that Nokia continually delivers a new mobile communication product every 25 days!

\section{Exploiting IT for Knowledge Management}

As early as in the $1980 \mathrm{~s}$, there were great expectations that knowledge-based computer systems (e.g. expert systems or decision support systems) should be exploited as a knowledge management (KM) tool to solve business problems. For close to two decades, the search for KM tools was centred on stand-alone information systems (IS) such as CASE tools or commercial expert system shells. But in retrospect, part of the problem was that system developers have focused too much, perhaps overly so, on developing "thinking machines", rather than designing these machines to augment human thinking. In other words, it appears that the roles of information management and knowledge management should be separated and played by machines and humans respectively. Researchers also came to realise that only human beings can take the central role in knowledge management, not computer systems even with their powerful information-processing capabilities (Stewart, 1991; 1993; 1995; Nonaka, 1991; Nonaka and Takeuchi, 1995).

Computers are just merely tools, however great their information-processing capabilities may be. It must therefore be acknowledged that while information generated by computer systems is a rich carrier of "interpretative knowledge" for potential action, "useful knowledge" resides in the user's subjective context of action based on that information. For this reason, the exploitation of technologies for knowledge management (KM) must be seen as a form of human activity, while being mediated by appropriate IT tools, fundamentally motivated towards a specific purpose. Yet, apart from the social dimension associated with knowledge creation, researchers have adopted 
varying interpretations that relate to mechanistic dimension such as codification or personalisation and the like. Nevertheless, the economic-rational view of modern organisations requires a more integrated perspective involving technological, organic and humanistic means of leveraging knowledge innovation for organisational growth (Hasan and Handzic, 2003; Harkema and Browaeys, 2002; Davenport and Prusak, 1998). But ultimately, it is the role of empirical research to enhance knowledge management practice for the pursuit of innovation.

\section{AN INTEGRATED MANAGEMENT FRAMEWORK}

\section{Motivation}

Currently, the mainstream KM literature in relation to innovation does not deal adequately the management of KI as an area of concern. Unlike innovation theorists, most writers concerned with knowledge management (KM) issues tend not to exhibit the same degree of understanding on the economic significance of innovation. On the other hand, innovation writers are often less able to articulate how KM practices can be applied as an effective management tool. Yet, virtually every organisation is grappling with the opportunities presented by $\mathrm{KM}$, including new ways to acquire, assimilate and share knowledge in innovation pursuits. By now, it is evident that the emergence of knowledge innovation is offering not only immense potential for organisations to gain a sustainable competitive advantage over rivals, but also the ability to improve organisational performance. For knowledge innovation to be employed successfully as a competitive tool would require a focused business strategy that harnesses knowledge management (KM) in ways that offer a new approach to innovation strategies (Blumentritt, and Johnston, 1999; Skyrme and Amidon, 1997). Hence, instead of investigating "what goes into the bolts and nuts of knowledge innovation", the current approach focuses on "which strategic aspects of management should knowledge innovation focus on" to offer insights into the strategic management of knowledge innovation (KI). Understanding the strategic $\mathrm{KM}$ issues in the context of IM is likely to provide insights into how the role of knowledge innovation can be better managed in areas such as implementation of ICT or utilisation of knowledge assets. Thus an integrated approach is proposed to guide those strategic aspects of management that would affect the evolution of knowledge innovation in organisations. However, so far, the lack of an integrative view of knowledge innovation (KI) leads to a certain degree of confusion. To better understand the evolution of knowledge innovation, fresh perspectives of KM are necessary. In particular, two areas of knowledge literature on KI have yet to be fully addressed. Firstly, a definition of knowledge innovation (KI) needs to be specified to put in perspective of its impact on the success of enterprises, economy and society; and to identify the key elements that underscore the critical importance of knowledge-based assets and the management actions required for innovation. Secondly, since a comprehensive model for understanding the nature of knowledge management $(\mathrm{KM})$ practices in innovation is not yet apparent in extant literature, integrating $\mathrm{KM}$ and IM within the same framework is required. However, two pertinent questions remain to be answered: One, what are knowledge-based assets? Two, what does a knowledge innovation really constitute?

\section{What are Knowledge-Based Assets?}

Not all information can be considered as "knowledge-based assets". Very often, organisations determine what information qualifies as knowledge-based assets, depending on the context and business objective. Besides being conceived as a "human" concept, the view of knowledge-based assets adopted in this article also includes the concept of "objects" that can be coded and stored, 
which in turn may be subsequently mobilised for innovation. In general, knowledge-based assets fall into two categories: explicit or tacit. Included among the former are patents, trademarks, business plans and marketing research - any information that can be documented, archived and codified, often with the help of information technology (IT). In the case of the latter, it is much harder to grasp as the information is contained in people's heads and the real difficulty lies in figuring out how to document, share and manage it effectively. Hence, it means that a highly integrative approach, to managing the processes for creating, classifying, storing, disseminating and utilising knowledgebased assets for innovation, should be adopted (Amidon, 1997; Drucker, 1988). Even if technologies like electronic mail, groupware, and instant messaging tools can be used to manage tacit knowledge, identifying it is itself a major hurdle in most organisations.

\section{What does a Knowledge Innovation really constitute?}

Notably, it was Drucker in the 1950s who first coined the term "knowledge worker", but it was only until fairly recent that corporate leaders, policy-makers and entrepreneurs began to strongly acknowledge that successful innovations are increasingly knowledge-intensive. Amidon (1997) has aptly described "knowledge innovation" as the creation, evolution, exchange and application of new ideas into marketable goods and services, leading to the success of an enterprise, the vitality of a nation's economy and the advancement of society. In gist, two key elements are present in the definition. One, it recognises that knowledge is a key component of innovation - not technology or finances. Two, the actions associated with managing the flow, use and handling of knowledge in an innovation process is another key component. However, it is less clearly delineated as to what extent the literature between KM and IM, as represented in Figure 4, can be drawn as insights into the management of knowledge innovation (Harkema and Browaeys, 2002; Miller and Morris, 1999; Rogers, 1995).

Figure 4: Management of Knowledge Innovation

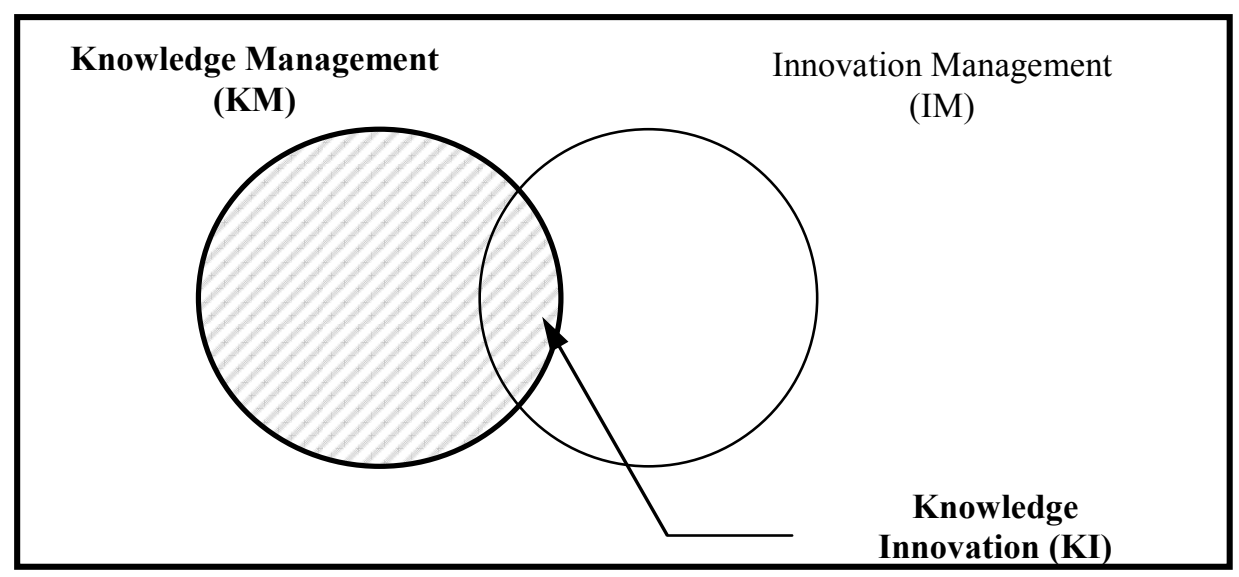

\section{Strategic Management of Knowledge Innovation}

With a diverse range of digitised repositories, IT tools and communities of best KM practices, organisations are racing to revolutionise their approaches to use knowledge-based assets for 
innovation. However, applying available KM tools alone that ran the gamut from standard, off-theshelf computer packages to sophisticated software designed to support knowledge management (KM) activities is inadequate. Insofar as knowledge innovation is concerned, it often involves unique and highly professional skills - which are difficult to be trained and learned. The role played by knowledge-based assets in innovation management (IM) is also undergoing changes. Because of the tacit nature of an organisation's knowledge and the need to sustain competitive advantage, current thinking points to the management of KI as an effective way to support organisational performance (Gupta and McDaniel, 2002; Clarke and Rollo, 2001; Probst, Raub and Romhardt; 1999).

Focusing on the management of KI is strategic because it is created through human exchanges and investments in continuous learning; and knowledge innovations are not stagnant but continually adjust in response to changing environments and market conditions. Hence, this article proposed that knowledge innovation should be guided by appropriate knowledge-centred principles, with supporting knowledge-sharing infrastructures to better facilitate knowledge-based initiatives. Nevertheless, the inputs of human responses, investment decisions, technological options and past experience should always be taken into consideration for the management of KI.

By employing an integrated management framework for knowledge innovation (KI) as shown in Figure 5 - in terms of perspectives on principles, infrastructures and initiatives, it would enable organisations to better fulfil their roles in these areas. Although the framework extends beyond any specific type of KM practices, tools and physical systems, its conceptual development is primarily based on a comprehensive overview of KM literature. Furthermore, while the actual KM implementation may be firm-specific and uniquely diverse, the framework nonetheless provides an integrative view of management thinking that would help organisations merge relevant concepts of $\mathrm{KM}$ with innovation management. 
Figure 5: An Integrated Management Framework

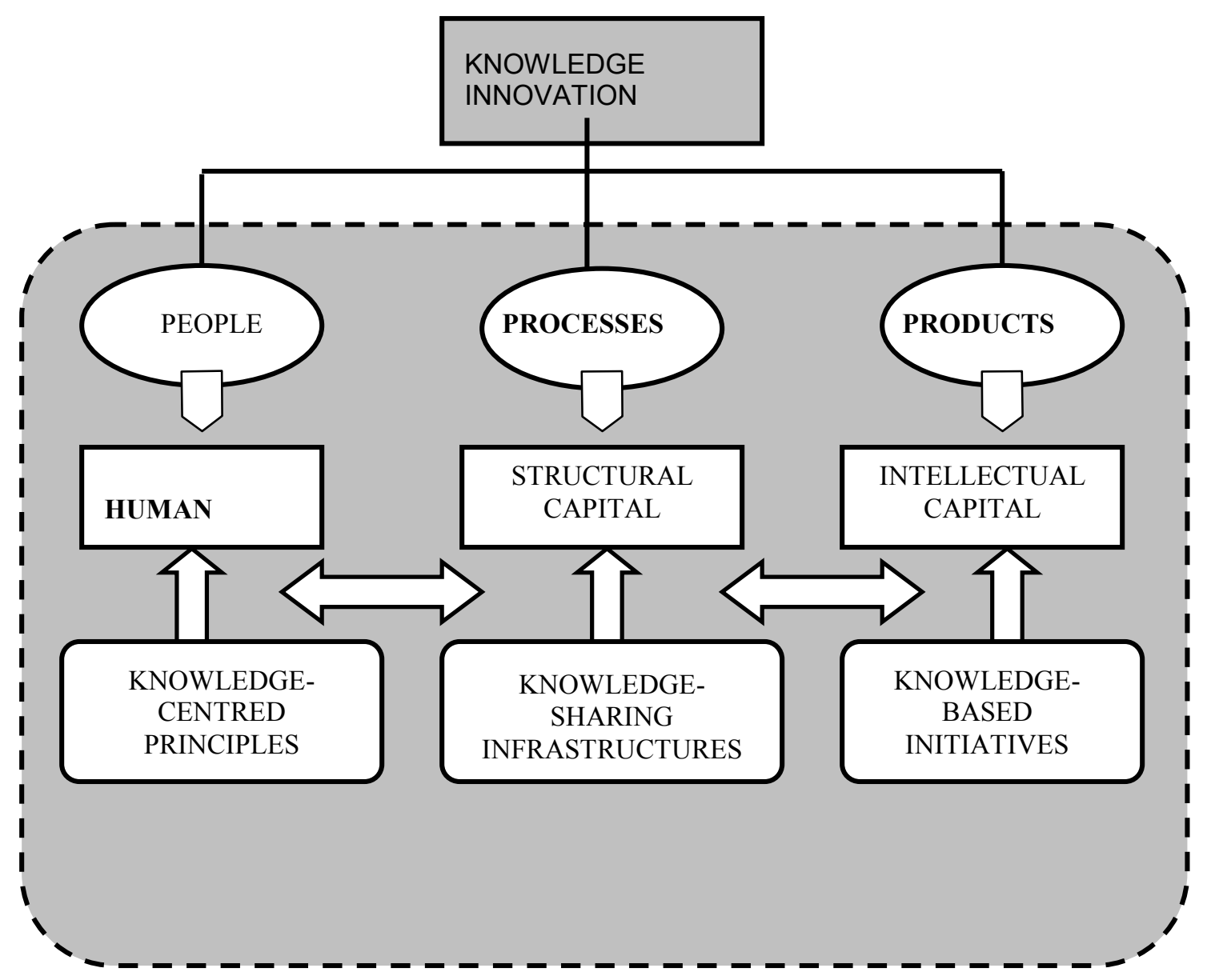

KNOWLEDGE-CENTRED PRINCIPLES

If knowledge management (KM) practices were to be incorporated into innovation management thinking as a competitive tool for supporting knowledge innovation, organisations must re-examine their role within a larger framework of KM practices, built on a mindset of knowledge-centred principles to be practised by the entire community of knowledge workers. This would then place a stronger emphasis on long-term strategic issues relating to knowledge management and thereby better support different forms of knowledge creation in organisations. To make headway along this line of emergent thinking, knowledge-centred principles that typify new approaches of managing knowledge capital for innovation, are identified through a distillation process. But more importantly, these principles incorporate the critical elements of knowledge management relevant to the innovation process. In contrast with other areas of management, six knowledge-centred principles seem to distinguish themselves between the management of knowledge innovation from the other conventional management approaches as outlined in Figure 6 (Harkema and Browaeys, 2002; Davis and Botkin, 1999; Miller and Morris, 1999; Skyrme and Amidon, 1997, Davenport, 1993). 
Figure 6: Knowledge-Centred Principles

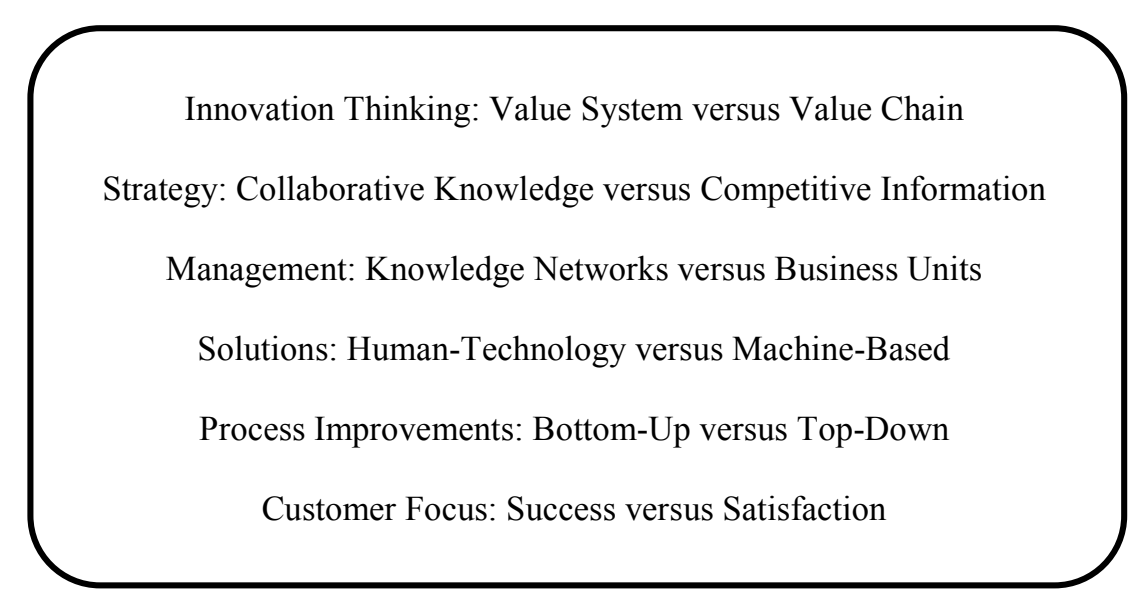

These knowledge-centred principles are summarised as follows:

- Understanding Innovation Value System (not Value Chain) - Value chain thinking is linear and static, while the innovation value system consists of non-linear and dynamic knowledge processes and represents interdependent relationships that need to be understood, considered and developed for successful knowledge innovation;

- Formulating Collaborative Knowledge Strategy (not Competitive Information Strategy) - Competitive information strategies create win-lose scenarios due to competition for a share of the same information pie, while collaborative knowledge strategies encourage win-win situations through symbiotic relationships by sharing knowledge assets and growing the knowledge pie for all stakeholders.

- Developing Strategic Knowledge Networks (not Strategic Business Units) Strategic business unit management tends to apply isolated islands of information assets, while the strategic knowledge networks foster the flow of knowledge assets between partners, customers, suppliers, internal and external units and other stakeholders, including competitors, in the innovation process.

- Constructing Hybrid Human-Technology KM solutions (not Machine-based KM solutions) - Human beings are better at "knowledge skills" while computers are more adept at "information tasks" such as collecting and categorising highly structured information that changes rapidly. To interpret knowledge within a broader context or to combine it with other types of information, or to synthesise unstructured knowledge, humans and machines must complement each other.

- Fostering bottom-up knowledge process improvements (not top-down "reengineering" of knowledge management approaches) - Highly creative and useful knowledge work carried out by autonomous knowledge workers often require less top-down intervention and more bottom-up spontaneity.

- Focusing on Customer Success (not Customer Satisfaction) - Customer satisfaction meets today's needs only, while a deliberate focus on customer success helps identify future requirements and unmet needs, which form the competitive 
forces for firm growth and business expansion.

Notwithstanding the recognition given to these knowledge-centred principles, many KM tools could also facilitate, to a certain extent, the management of knowledge innovation (KI). But more importantly, managing KI should not be seen as a technology-centred concept. While technological tools may support its management, it must be borne in mind that management decisions relating to knowledge innovation are ultimately based on who (people), what (knowledge assets) and why (business objectives). For this reason, organisations that went about solely installing large-scale centralised IT systems or any advanced IT tools in the hope that they have thus established a successful KI programme may be disappointed in the long haul.

\section{KNOWLEDGE-SHARING INFRASTRUCTURES}

The driving force behind the rapid transformation to greater inter-connectivity, accelerated data transmission and reduced costs of communications is none other than information and communication technologies (ICT). Undoubtedly, the greatest benefit of ICT is its reach and one of its most important roles in KM is its knowledge sharing advantages. Currently, of the ICT available at today's workplace that have the most profound impact on KM practices is that of the Internet and related technologies - which offers an incredible information source direct to the end-users without the need to involve an intermediary such as information professionals (CIO, 1996).

Although the Internet has been growing in stature and impact, its knowledge-sharing considerations are almost entirely confined to its information role. Whether it really shares "usable knowledge" for developing innovations is still subject to debate. While the cost of building national level knowledge-sharing infrastructures may be very high, there are also hardly any equally cost-effective technological alternatives. In countries where the knowledge-sharing infrastructure is weak (no optical fibre link to world's information superhighway, for instance), the dial-up access charges may be even higher than the Internet usage costs itself. But once the infrastructure is established, the cost of propagation technology can be very low. Nevertheless, knowledge sharing continues to be impeded by the digital barrier unless there is a universal access to ICT in all parts of the world.

Internet heralds the way for collaborative sharing of knowledge-sharing assets. To effectively implement knowledge-sharing infrastructures for KI, organisations should consider, at a minimum, ample support for the processes of codifying and storing knowledge, creation of knowledge maps (or corporate directories), sharing of best practices, and developing knowledge networks (Maryam and Leinder, 2001; Davenport and Prusak, 1998). For organisations to better exploit the use of the Internet in the management of knowledge innovation, an integrative approach to implementing its knowledge-sharing structures of ICT is required. Viewed from KM perspectives, the knowledgesharing infrastructures of the Internet and its related technologies should possess the following five characteristics (Barth, 2000; Miller and Morris, 1999; Strassmann, 1997) as shown in Figure 7:

- It uses a widely-supported communications standard protocol - which means that it is universally accessible from multiple locations and through different computer platforms;

- It offers world-wide access, with increasingly more international service providers (ISP) - which means that individuals, who travel a lot, can use the Internet like a corporate network without building an in-house option;

- It avails end-user software, such as electronic mail and browsers to be universally available at low cost (and often free) - which means that it is cost-effective to implement on an enterprise-wide basis; 
- It employs a high-speed, broadband, digital network based on optical fibre cables with limitless bandwidth - which means that it provides quick access at an affordable cost;

- It provides a quick means of publishing information, through the World Wide Web, that can be shared world-wide - which means that the universal repository of information resources can be updated and widely shared at an attractive cost.

Figure 7: Knowledge-Sharing Infrastructures

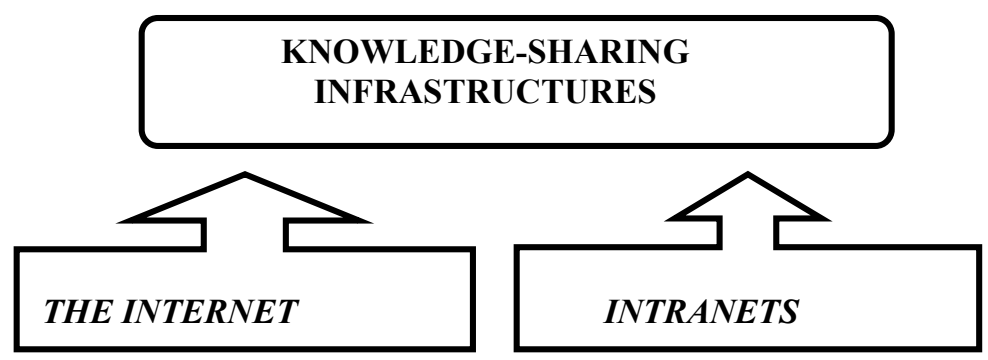

- Uses widely-supported communications standard protocol;

- Offers world-wide access;

- Avails end-user software;

- Employs a high-speed, broad-band, digital network based on optical fibres;

- Provides means of publishing information.

Additionally, due to the growing interest of organisations who want to share information, knowledge-sharing infrastructures have expanded to include the use of Intranets for better accessibility in a corporate environment. The advantages of using Intranets are similar to those that use the Internet in external information access and communications. Because end-users are familiar with browser interfaces, information can be shared across different local area networks and computer platforms, and published information is instantly available over the whole network. Besides, information may be presented in different formats, like word-processed documents. Furthermore, Intranets can host transaction and database applications with the Web browser being the universal interface to different "back-end" systems. Whatever the format and content may be, an Intranet essentially facilitates the sharing of internal information, while the Internet gateways external information.

\section{KNOWLEDGE-BASED INITIATIVES}

Differences in perception of KM issues exist in various business activities - for example, how much information should be involved before we consider a business activity as "knowledge-intensive"? Seemingly, what was more crucial is not whether information was utilised, but whether the business activities involve the right kind of knowledge-based initiatives that produce intended benefits. For a 
right knowledge-based initiative to take place, quantity rarely equals quality, and indeed, the objective of it is to identify "knowledge gems" from a "sea of information".

Whether a knowledge-based initiative contributes to an innovation process depends largely on the interpretation of knowledge innovation (KI) as depicted in Figure 8. There are two distinct interpretations of KI that give rise to various knowledge-centred initiatives, which eventually can be translated to knowledge capital through value creation. The first interpretation, which centres on the traditional information-processing model of knowledge management, assumes a problem as given and the solution as based upon a pre-specified notion of the business environment. The second interpretation, which revolves around human imagination and creativity as a new mental model of knowledge creation, constructs the definition of the problem from the knowledge available at a certain point in time and context (Malhotra, 2000a; 2000b; 1997; Yoneji, 1990). Based on a review of current literature on KM practices centred on organisations which host information in the Internet, nine knowledge-based initiatives have emerged to be of considerable significance to knowledge innovation in products, processes and people (Amidon, 1997; Skyrme and Amidon, 1997; De Long and Davenport, 1996; Skyrme, 1991). They are listed below:

\section{Products}

- $\quad$ Structuring and mapping knowledge - such as developing typologies or synthesising different knowledge types;

- Developing knowledge databases - documenting best practices, expert directories, market intelligence and so on;

- Embedding knowledge in new products and services - such as the introduction of smart products;

\section{Processes}

- Capturing and re-using information as knowledge - such as utilising old project deliverables as source materials to develop specifications for a new project;

- Sharing of knowledge or lessons learnt about knowledge processes - from one part of the organisation to another, through distribution, dissemination or personal interactions;

- Measuring and managing the value of knowledge assets - such as attaching an economic worth to the ownership of patents or managing the rights of these patents;

\section{People}

- Creating knowledge or intellectual capital teams - to help identify and audit intangible knowledge-based assets using people from multiple disciplines and to develop new practices of knowledge management;

- Forming people-oriented knowledge centres - establishing focal points for the development of knowledge skills, managing and enhancing knowledge databases and facilitating knowledge flow;

- Using collaborative technologies for knowledge exchange between people - the implementation of Intranets (internal Internet), electronic mail, Lotus Notes, groupware for multiple-user access. 
Figure 8: Knowledge-Based Initiatives

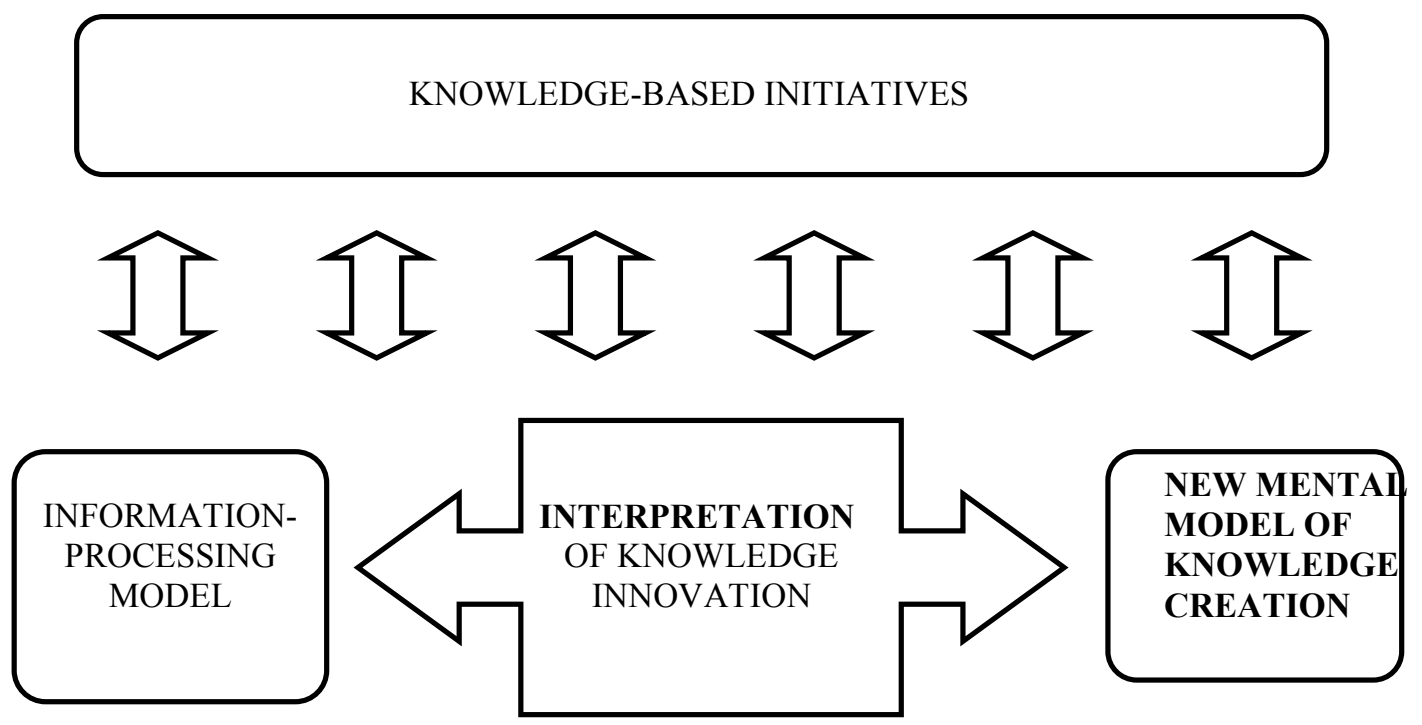

While knowledge-based initiatives need not necessarily be implemented via the Internet, the relative ease of use of Internet technology, its cost-effectiveness and immediate availability to a global audience of users in more than 190 countries offer many advantages. Three advantages are cited here. Firstly, the Internet performs exceptionally well in facilitating remote and rapid access, through network connections and enhancing global communications at a low cost. Secondly, with major technological developments on the Internet occurring frequently, it offers quantum improvements in access efficiency using browsers, search engines and intelligent software that search the most relevant information for end-users. Thirdly, since knowledge management (KM) activities are no longer implemented through stand-alone point solutions, such as expert systems or group decision support systems, the Internet offers a means for enterprise-wide knowledge-based initiatives to be better accomplished through groupware systems like Lotus Notes and Intranets.

\section{FUTURE CHALLENGES FOR KNOWLEDGE INNOVATION}

While there may be extensive literature written in the two management areas, namely knowledge management (KM) and innovation management (IM) as separate areas of concern, limited research was done specifically on the management of knowledge innovation (KI). This article integrates the two management areas: KM and IM, each having a momentum of its own, into one singular focus to foster new thinking in identifying sustainable competitive advantage through knowledge innovation. It suggests that to effectively manage knowledge innovation in any organisation, three strategic aspects of management should be looked into as a whole. One, organisations should embrace a mindset of knowledge-centred principles to better maximise the value of their knowledge capital for innovation. Two, organisations should implement knowledge-sharing infrastructures through the use of ICT to better enhance the knowledge-based assets required for the pursuit of innovation. Three, organisations should promote knowledge-based initiatives to better facilitate the creation of knowledge innovation. To address the management of knowledge innovation (KI), an integrated 
management framework is thus proposed to better fulfil organisational roles. But to fully exploit the benefits of knowledge innovation (KI), three challenges that merit attention have been identified as follows:

Firstly, as knowledge innovation encompasses the use of various types of knowledge assets; and social, economic and other forms of tacit knowledge, the innovation process requires the assimilation of human imagination, intuition and creativity at all levels to achieve success. To unleash the potential of knowledge innovation, the challenge is to permeate knowledge-based initiatives to various layers of society - industrial, organisational and humanistic structures. This would then enable organisations and individuals to utilise knowledge capital to participate in the core activities of knowledge innovation.

Secondly, although the objective of knowledge innovation is to improve organisational performance, it should not be viewed as the "magic cure" for ailing organisations. Paradoxical as it may sound, the fewer KM practices an organisation requires in its pursuit of innovation, is also a reflection that it has championed knowledge-centred principles adequately in its business. The challenge posed to organisations is to identify, create and acquire new knowledge assets all the time, and to make these assets readily available, transparent and freely mobile for individuals involved in knowledge innovation.

Thirdly, for knowledge innovation to flourish, it must be fostered within an enabling environment of collaborative enterprises. Since knowledge innovation constitutes the "discovery of new knowledge assets", oftentimes based on competencies and talents inside and outside an organisation, collaboration between enterprises should be recognised, encouraged and valued. Ultimately, the challenge lies in strengthening the role of all stakeholders in a knowledge enterprise towards collaboration - embracing a knowledge-oriented culture and nurturing a knowledge-sharing ecosystem. After all, the success of any knowledge innovation depends on the extent of collaboration amongst individuals who have created the knowledge - the very trait that make knowledge useful, beneficial and valuable to society.

$\mathrm{n}$ conclusion, the ability of an organisation to capture, develop and use knowledge-based assets for innovation constitutes a source of sustainable competitive advantage. However, the entire process of leveraging knowledge innovation is likely to be encountered with failure if the knowledge management aspects of innovation are left to chance. Furthermore, like all types of innovation, knowledge innovation, too, is often managed with a business objective in the context of "imperfect conditions". It should therefore be acknowledged that the ultimate goal of managing knowledge innovation effectively is perhaps one for all "knowledge workers" to strive for, but never to be completely addressed. Nevertheless, it is clearly outlined in this article that an integrated management approach, depending on organisational context and business objective, with due considerations given to knowledge-centred principles, knowledge-sharing infrastructures and knowledge-based initiatives, stands a far better chance of success over the long-term. I

\section{REFERENCES}

Amidon, Debra M. (1997). Innovation Strategy for the Knowledge Economy: The Ken Awakening, Boston, MA: Butterworth-Heinemann.

Barth, S. (2000). “Defining Knowledge Management", CRM Magazine (4 July 2000), Information Today Inc.

Blumentritt, R. and Johnston, R. (1999). "Towards a Strategy for Knowledge Management”, Technology, Analysis and Strategic Management, Vol. 11, No. 3, pp. 287-300. CIO (1996). "Librarians at the Gate”, Webmaster Magazine, CIO (September). 
Clarke, T., and Rollo, C. (2001). "Capitalizing Knowledge: Corporate Knowledge Management Investments”, Creativity and Innovation Management, Vol. 10, No. 3; pp. 177-188

Davenport, T. (1993). Process Innovation: Re-engineering Work through Information Technology, Boston, MA: Harvard Business School Press.

Davenport, T. H., and Prusak, L. (1998). Working Knowledge: How Organisations Manage What They Know, Boston, MA: Harvard Business School Press.

Davis, Stan and Botkin Jim (1999). "The Coming of Knowledge-Based Business", Harvard Business Review, pp.165-170 (September-October 1999).

De Long and Davenport, B. (1996). "What is a Knowledge Management Project?" Ernst \& Young LLP Centre for Business Innovation, Research Note CBI311.

Drucker, Peter (1988). "The Coming of the New Organisation”, Harvard Business Review, pp. 4553 (January-February 1988).

Drucker, Peter (1994). “The Theory of Business”, Harvard Business Review, pp. 95-104 (September-October 1994).

Fahey, L. and Prusak, L. (1998). "The Eleven Deadliest Sins of Knowledge Management”, California Management Review, Vol. 40, No. 3, pp. 231-246.

Giget, Marc. (1997). “Technology, Innovation and Strategy: Recent Developments”, International Journal of Technology Management, Vol. 14, No. 6, pp. 613-634.

Goh, Andrew (2004). "Enhancing Competitiveness Through Innovation: Issues and Implications for Industrial Policy-Making", International Journal of Applied Management and Technology, Vol. 2, No.2, pp. 88-113 (May 2004).

Gold, A., Malhotra, A., and Segars, A. (2001). "Knowledge Management: An Organizational Capabilities Perspective”, Journal of Management Information Systems, Vol. 18, No. 1, pp. 185-214.

Gupta, A., and MacDaniel, J. (2002). “Creating Competitive Advantage by Effectively Managing Knowledge: A Framework for Knowledge Management”, Journal of Knowledge Management Practice, Vol. 3, No. 2, pp. 40-49.

Hasan, H. and Handzic, M. (2003). Australian Studies in Knowledge Management, Australia: UOW Press (October 2003).

Harkema, S.J.M. and Browaeys, M. J. (2002). "Managing Innovation Successfully: A Complex Process", European Academy of Management Annual Conference Proceedings, EURAM 2002, Brussels.

Lindgren, R. and Henfridsson, O. (2002). "Using Competence Systems: Adoption Barriers and Design Suggestions”, Journal of Information and Knowledge Management, Vol. 1, No. 1, pp. 65-78.

Malhotra, Y. (1997). "Knowledge Management in Inquiring Organisations", Proceedings of $3^{\text {rd }}$ America Conference on Information Systems (Philosophy of Information Systems Minitrack), Indianapolis, IN, August 15-17, 1997.

Malhotra, Y. (2000a). Knowledge Management and New Organisation Forms: A Framework for Business Model Innovation, Knowledge Management and Virtual Organisations, Hershey, PA: Idea Group Publishing.

Malhotra, Y. (2000b). "Knowledge Management for E-Business Performance", Information Strategy: The Executives Journal, Vol. 16, No. 4, pp. 5-16.

Maryam, M. and Leidner, D. (2001). "Knowledge Management and Knowledge Management Systems: Conceptual Foundations and Research Issues”, MIS Quarterly, Vol. 25, No. 1, pp. 107-136.

Miller, W.L. and Morris, L. (1999). Fourth Generation R\&D: Managing Knowledge, Technology and Innovation, Canada: John Wiley \& Sons Inc. 
Nonaka, Ikujiro (1991). “The Knowledge-Creating Company”, Harvard Business Review, pp. 96104 (November-December 1991).

Nonaka, Ikujiro and Takeuchi, Hirotaka (1995). The Knowledge Creating Company: How Japanese Companies Create the Dynamics of Innovation, New York: Oxford University Press.

O'Dell, Carla (1996). “A Current Review of Knowledge Management Best Practices”, Knowledge Management 96 Conference, Business Intelligence, London (December).

Probst, G., Raub, S. and Romhardt, K. (1999), Managing Knowledge: Building Blocks for Success, London, UK: John Wiley and Sons.

Rogers, E (1995). Diffusion of Innovations (4 ${ }^{\text {th }}$ Edition), New York: The Free Press.

Skyrme, David J. (1991). "Knowledge Networking”, The Intelligent Enterprise, Aslib, Vol. 1, No. 9/10, pp. 9-15 (November).

Skyrme, David J. and Amidon, Debra M. (1997). Creating the Knowledge-based Business, London, UK: Business Intelligence.

Stewart, Thomas A. (1991). "Brainpower", Fortune, pp. 44-56 (3 June).

Stewart, Thomas A. (1993). "Your Company's Most Valuable Asset: Intellectual Capital”, Fortune, pp.51-56 (3 October 1993).

Stewart, Thomas A. (1995). "Trying to Grasp the Intangible”, Fortune, pp.157-161 (2 October).

Storey, J. and Barnett, E. (2000). "Knowledge Management Initiatives: Learning from Failure", Journal of Knowledge Management, Vol. 4, No. 2, pp. 145-156.

Strassmann, P.A. (1997). The Squandered Computer: Evaluating the Business Alignment of Information Technologies, New Canaan, CT: Information Economics Press,

Yoneji, Masuda (1990). 'The Information Society as a Post-industrial Society', Institute for the Information Society, Tokyo. Translated into English as Managing in the Information Society, Basil: Blackwell Publishers. 